\title{
TOWARDS A SCORING SYSTEM FOR QUANTIFYING THE OBJECTIVE WELL-BEING OF INDIA AND ANALYSIS OF ITS COMPONENT INDICATORS
}

\author{
Aditya Manikantan, Ameya Joshi \\ Department of Computer Science and IT, Ramnarain Ruia Autonomous College, \\ Mumbai - 400019, Maharashtra, India
}

\begin{abstract}
The well-being of an individual is very subjective in nature. A rich person can be miserable while at the same time a middle class person can be content with the way he/she is. Officially it is defined as "the state of being comfortable, healthy or happy" [1]. However, well-being is a much broader concept than moment-to-moment happiness. A person's wellbeing can encompass a number of factors ranging from health indicators to wealth related indicators. In this paper, we are proposing a means to objectively analyze the well-being (OWBA) of individuals in India. We first start by finding the most contributing indicators towards a person's well-being in India. Finally, we present a way to calculate the objective wellbeing score (OWBS) of the population by taking into account these important indicators.
\end{abstract}

Keywords- Well-being, Social issues, Health, Economy, Education, Objective well-being score, Human development

\section{INTRODUCTION}

India has made significant strides in improving multiple sectors such as Health, Social Inequality, the Economy, and Education since the past couple of decades. For example, the proportion of the rural population with access to electricity has more than doubled from $37.45 \%$ in 1995 to $92.93 \%$ in 2018 [2]. The share of seats held by women has also risen from $7.34 \%$ in 1995 to $13.48 \%$ in 2019 [2]. However, not all indicators have shown an improvement. The government expenditure on health has dropped by more than $1 \%$ of the total GDP since 2000 [3]. Also, the expenditure in Tertiary education is showing a steady decline in recent years [4].

Objective Well-Being Analysis (OWBA) aims to analyze and find the most important indicators towards a person's wellbeing from multiple sectors such as Health, Social, Education and Economy. It shows the changes in trends across multiple decades, increase/decrease in disparity between the rich and poor or men and women etc. The analysis also presents important correlations among these sectors. Finally, based on this analysis, we rank the sectors having the most influence on a person's well-being and assign respective weights for the Objective Well-Being Score (OWBS) calculation. OWBS condenses the distribution of important indicators over the population into a single number, similar to a Human Development Index (HDI) [5], which can be used to compare results over time or locations.

OBWA can help determine the sectors which require improvement. This analysis goes in-depth to pinpoint the indicators which are having the most impact on a sector's decline. The important correlations can illustrate how multiple sectors can work in conjunction with each other to improve a certain aspect. The OWBS can objectively represent where the well-being of the people of our country stands at present. By comparing the OWBS across time, we can determine whether there has been an improvement or decline in well-being and by how much.

Referring Maslow's Hierarchy of Needs [6], CDC's definition of wellbeing [7], UK ONS's well-being definition [8], and well-being as defined in the Stanford Encyclopedia of Philosophy [9], we concluded that the following general factors are used to define wellbeing or a sense of wellness:

1) Physical health

2) Mental health

3) Ability to take important life decisions

4) State of personal finances

5) Ability to climb the social hierarchy

Furthermore, the above factors can be grouped into 4 distinct indicators: Health, Social, Economic, and Education.

Hence, for our study, we have defined well-being as a combination of individual determinants that positively or negatively influence the above factors.

There are other similar metrics such as HDI [5] which measures the human development of a country based on similar factors: Health, Education and Economy. However, OWBS is specifically made for India. Along with the above three indicators, it also includes Social factors and is more comprehensive in terms of coverage of indicators concerning India. 
International Journal of Engineering Applied Sciences and Technology, 2021

Vol. 6, Issue 2, ISSN No. 2455-2143, Pages 151-160

Published Online June 2021 in IJEAST (http://www.ijeast.com)

\section{MATERIALS AND METHODS}

\section{A. Data Source-}

Data for the Economy indicators along with data segregated between urban and rural regions were collected from the World Development Indicators database [3] and the Sustainable Energy for All (SE4ALL) database [2]. These databases are part of the World Bank collection of development indicators [3], compiled from officially recognized international sources. It presents the most current and accurate global development data available, and includes national, regional and global estimates

The Education indicators data were collected from the UNESCO Institute for Statistics [4] which holds around 2,500 internationally comparable education indicators for access, progression, completion, literacy, teachers, population, and expenditures. The indicators cover the education cycle from preprimary to tertiary education. The query also holds learning outcome data from international learning assessments (PISA, TIMSS, etc.), equity data from household surveys, and projection data to 2050. Data for the health indicators were collected from the World Health Organisation, Global Data Observatory [10] which provides access to over a 1000 different health indicators.

\section{B. Objective well-being analysis-}

Our goal was to find the key indicators affecting a person's well-being. We accomplished this by first analyzing indicators from each of the 4 main factors, Health, Social, Economy, and Education, individually.

We plotted various uni-variate and bi-variate graphs to analyze change in trends across time and decades. For example this included analysis such as finding the rate of female enrollment in tertiary education or finding whether there has been an increase or decrease in the Gross National Income (GNI) per capita since the last decade. Furthermore, we used Pearson correlation [11] to find the correlations among the indicators and performed regression analysis to find the influence some given indicators have on another.

Finally, based on our research, domain knowledge, and above analysis we grouped indicators across different sectors to find correlation across sectors. For example, this included finding the effect disparity between men and women has on the economy or how education influences the mortality rate of an individual.

\section{Objective well-being score-}

After identifying the key indicators, we moved on to calculating the final well-being score. The score would range from 0 to 1 with 1 indicating that the well-being of individuals in the country is at its best (utopia) and 0 being worst (dystopia).

Before we could calculate the final score, we had to get an index score for each of the 4 main factors: Health, Social, Economy and Education. These indices too will have a value ranging between 0 to 1 which would indicate how well a particular sector is performing. The Index score for a particular sector was calculated by taking the arithmetic mean of the key indicators in the sector. However, many indicators belonged to a different scale and units. Therefore, before we could begin, we had to first normalize scores between 0 and 1 [12].

So, values of indicators containing percentages between 0 $100 \%$ were simply divided by 100 . Some numeric values such as age were divided by 100 too. Other numeric values like population had to be divided by the total population of India for that year to scale the value between 0-1. For GNI and GDP, to get a scaled value relative to other countries, we found the $3^{\text {rd }}$ highest and $3^{\text {rd }}$ lowest values globally (to avoid outlier values) and performed min-max scaling. So for example, the value of GNI of India for a given year would be,

Scaled GNI $=\frac{\text { Actual GNI value }- \text { Minimum value }}{\text { Maximum value }- \text { Minimum value }}$

Similar indicators like cases of TB or malaria per year were normalised in the same way by first looking at the global rankings and taking the respective maximum and minimum values.

The normalised values for positive indicators (indicators which contribute towards well-being) were left as it was. However, the normalised values for negative indicators (indicators which hampers well-being) were subtracted from 1, which adds a penalty to the overall index if the negative indicator value is high.

The final well-being score (OWBS) was obtained by taking the arithmetic mean of these indices. So it was calculated using the formula:

$$
\text { OWBS }=\left(I_{\text {Social }}+I_{\text {Health }}+I_{\text {Economy }}+I_{\text {Education }}\right) / 4
$$

However, this formula assumes that each indicator plays an equal part in a person's well-being, which is not the case. So, based on the OWBA, we have assigned respective weights to each Index which adds up to 100 .

$$
\text { OWBS }=\left(\left(I_{\text {Social }} \times W_{S}\right)+\left(I_{\text {Health }} \times W_{H}\right)+\left(I_{\text {Economy }} \times W_{\text {Eco }}\right)+\left(I_{\text {Education }} \times W_{\text {Edu }}\right)\right) / 100
$$

Dividing by 100 to scale the score between 0 and 1 .

We referred to Maslow's hierarchy of needs [6] and Alan Campbell's quote [13] and concluded that mental health is more important than physical health or other factors when it comes to determining a person's well-being. We see multiple examples of this in real life as well [14]. The social factor consists of multiple sub-factors or indicators like socio-economic conditions and discrimination on grounds of class, caste, sex, and all of these directly affect a person's mental health. Since we have established that mental health is the most important determinant of overall well-being, we decided to give the social factor the highest weightage $(40 \%)$ in the formula.

While health is obviously a very important factor for determining well-being, we cannot understate the enormous impact that economic factors like a government's expenditure on public health and the state of a person's finances have on the 


\section{International Journal of Engineering Applied Sciences and Technology, 2021 \\ Vol. 6, Issue 2, ISSN No. 2455-2143, Pages 151-160 \\ Published Online June 2021 in IJEAST (http://www.ijeast.com)}

ability to access healthcare[15]. That is why we decided to assign equal weights ( $25 \%$ each) to the health and economic factors.

We felt that education alone does not greatly influence any of the other three main factors and nor does it guarantee heightened feelings of well-being. For example, Alan Turing, one of the most influential people to advance computer science, obtained his $\mathrm{PhD}$ from Princeton. However despite this, he was charged with "gross indecency" as homosexual acts were illegal in those days in UK. This led to his suicide as was forced to be chemically castrated as punishment [16]. Therefore, while education is important in a person's life, we placed it at the bottom of our hierarchy and gave it the least weight (10\%). Hence, the final formula we get is:

$$
\text { OWBS }=\left(\left(I_{\text {Social }} \times 40\right)+\left(I_{\text {Health }} \times 25\right)+\left(I_{\text {Economy }} \times 25\right)+\left(I_{\text {Education }} \times 10\right)\right) / 100
$$

\section{OBJECTIVE WELL-BEING ANALYSIS}

\section{A. Social Factor:}

For analysis on social indicators we'll primarily focused on two social segments:

i. Disparity between Rich and Poor

ii. Disparity between Men and Women

Understanding this could help us understand whether there has been any improvement in these segments and where the government should focus their resources to improve. Apart from this it will also help us understand how social factors influence other sectors of India such as Health, Education and Economy.

i. Disparity between Rich and Poor:

\section{A.1. Income share:}

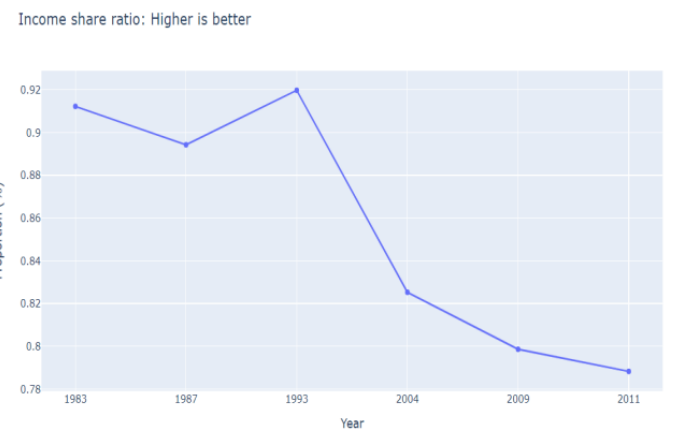

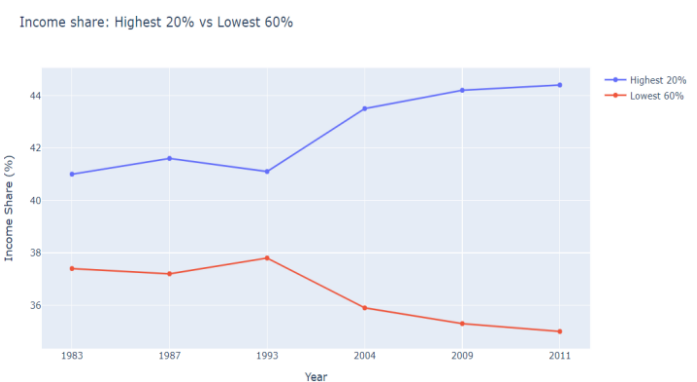

Fig.1A. Income Share Ratio Fig. 1B. Income Share: Highest $20 \%$ vs Lowest $60 \%$

Just the richest $1 \%$ of the population has 1.14 times the wealth of the poorest $40 \%$. There is a huge disparity in the wealth distribution between the rich and the poor. But, this disparity only seems to be widening every year. With a $3.6 \%$ gap in 1983 to a $9.4 \%$ gap in 2011 , which is almost a $62 \%$ increase in the gap in 28 years.

\section{A.2. Social Security:}

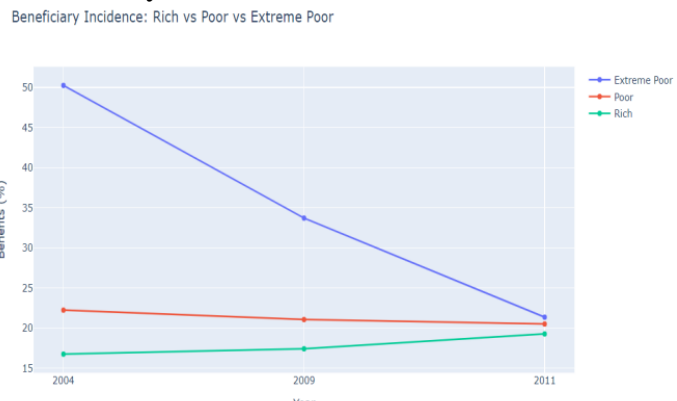

Fig. 2. Beneficiary Incidence: Rich vs Poor vs Extreme Poor

Huge improvement in the Beneficiary incidence in extreme poor bringing it down from 50.3\% in 2004 to $21.4 \%$ in 2011. The gap has drastically narrowed between the rich, poor and extreme poor.

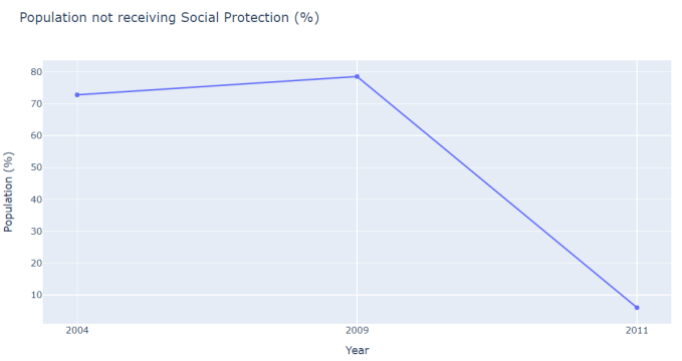

Fig. 3. Population not receiving Social Protection (\%)

Major strides had been taken in the direction of social protection coverage. The percentage of the population not receiving social protection saw a steep decline from $78.5 \%$ in 2009 to just $6 \%$ in 2011.

\section{A.3. Poverty Line:}




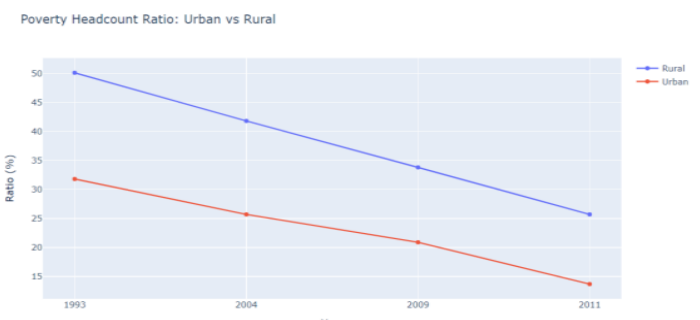

Fig. 4. Poverty Headcount Ratio: Urban vs Rural

Both urban and rural poverty have shown a decrease in the headcount of the population. From 1993 both have almost halved in numbers. On average the number of people in urban areas is almost $20 \%$ less than those in rural areas. Along with this, the rate of decrease of poverty in urban areas is slightly higher $57 \%$ compared to $49 \%$ in rural areas.

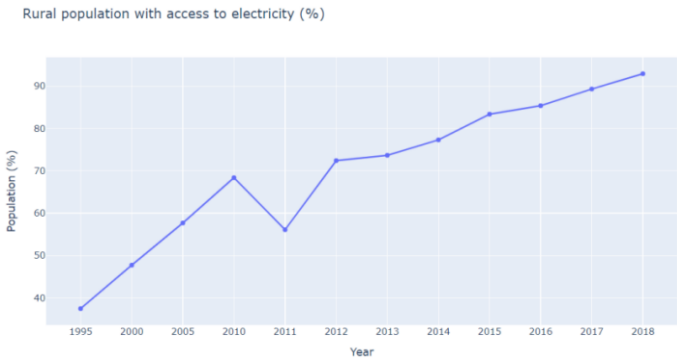

Fig. 5. Rural Population with access to electricity (\%)

Major advancement has been made in the rural population gaining access to electricity. The graph shows a sharp incline from $37.45 \%$ of rural population having electricity in 1995 to $68.37 \%$ in 2010. However, the following year showed a slump by falling down to $56 \%$ in 2011. Following this, the graph has shown a constant increase ever since and finally peaking at $93 \%$ in 2018. Therefore, we can see that progress towards providing electricity in rural areas has been astounding.

\section{ii. Disparity between Men and Women}

\section{A.4. Suicide Rate:}

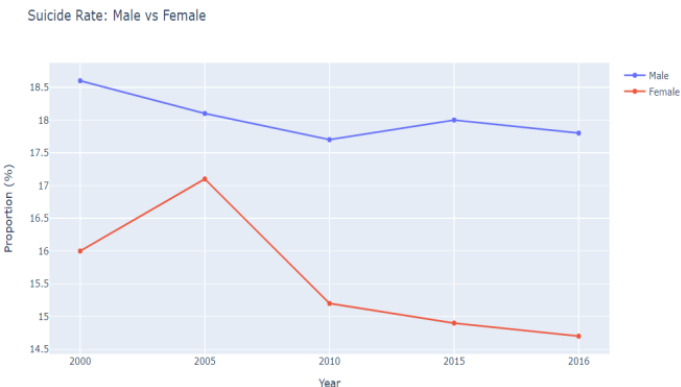

Fig. 6. Suicide rate: Male vs Female

Men have a $3 \%$ higher mean suicide rate of $18 \%$ than women at $15.5 \%$. The suicide rate for women peaked at 2005 following which there has been a gradual decrease ever since. However, suicide rate of men has more or less remained constant after 2010 .

\section{A.5. Child Marriage:}

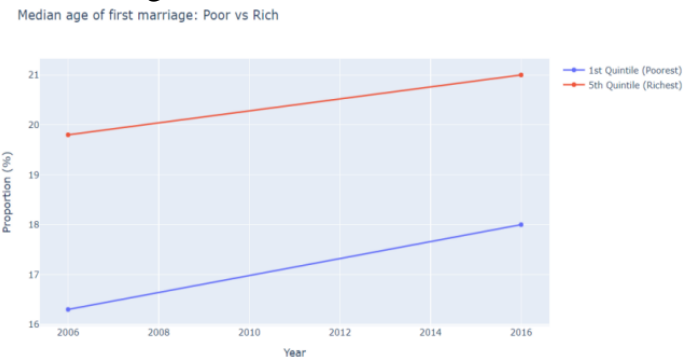

Fig. 7. Median age of first marriage: Poor vs Rich

There is a clear difference between the median age of first marriage between the rich (quintile 5) and poor (quintile 1). On average the median age of the rich is 3 years greater than the poor. In fact, the average age of marriage in the poor was below the legal age in 2006. However, the median age of both quintiles has increased by 2 since 2006 .

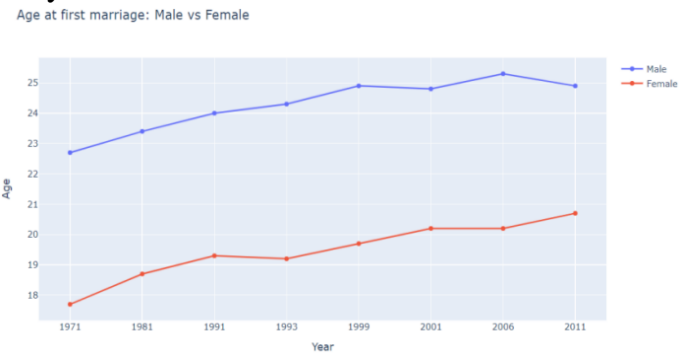

Fig. 8. Age at first marriage: Male vs Female

Average age of first marriage of men is almost 5 years above women. However, the average age of both has seen a constant increase in the last 50 years. Average first marriage age of women rose from 18 in 1971 to 21 in 2011 and for it rose from 23 in 1971 to 25 in 2011 . Also the gap between both seems to be decreasing.

A.6. Education:

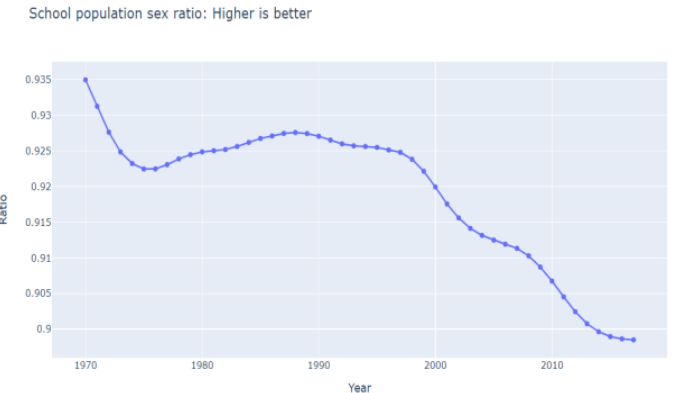

Fig. 9. School population sex ratio: Higher is better

The school population sex ratio is showing a constant decline from 0.93 in 1970 to 0.89 in 2017. Although the number of children enrolling in school has risen since 1970, the gap 
between male and female enrollment is widening

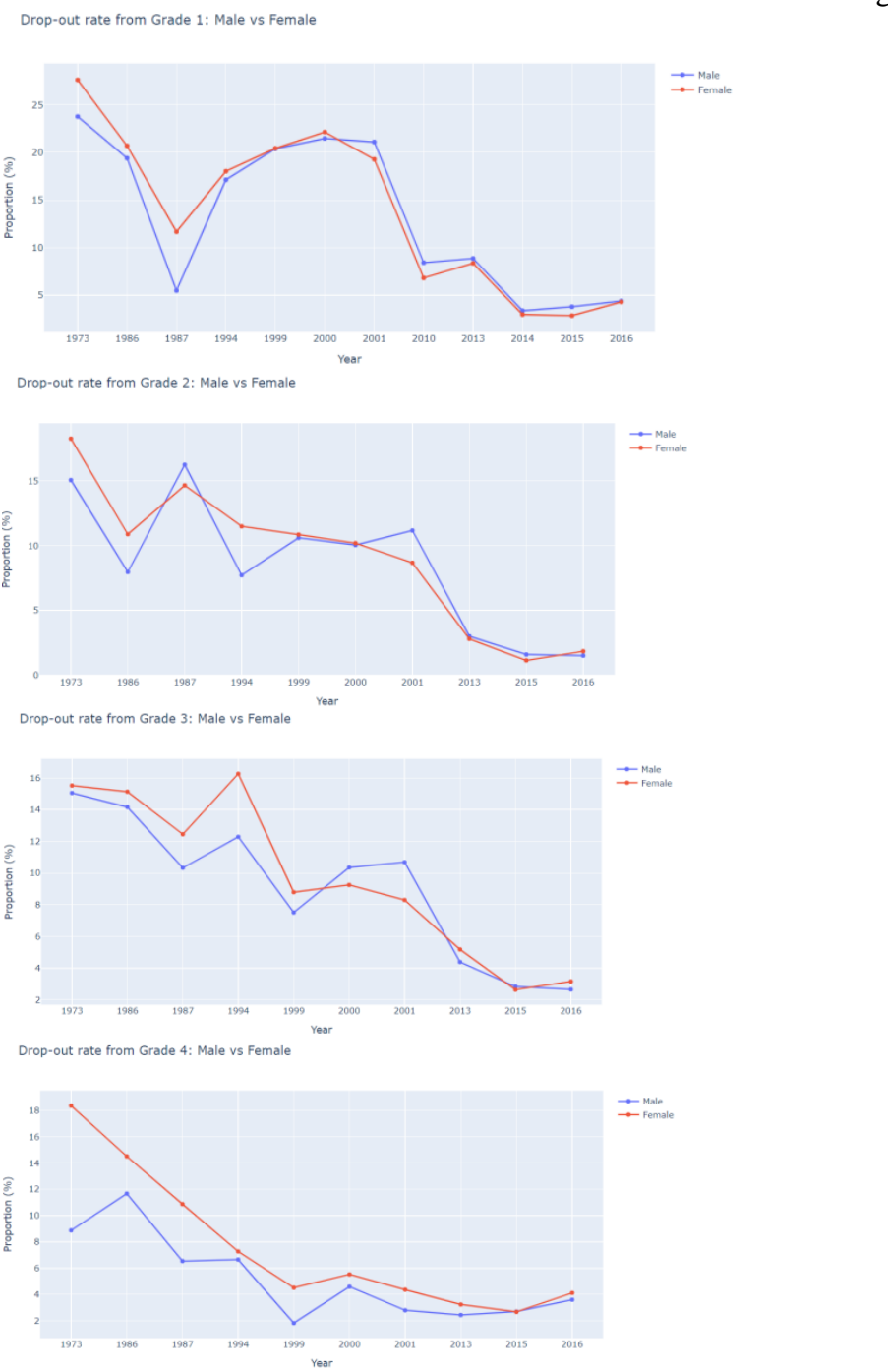

Fig. 10. Drop-out rate from Grade 1-4: Male vs Female

From Grade 1 to 2 men seem to have a higher dropout-rate on average. However, from grade 2 to 3 we see an increase in the drop-out rate of women.

Furthermore, there has been a steep decline in the average dropout rates from above 15\% in 1973 to around 3\% in 2016. Even the disparity between the drop-out rate of men and women have narrowed through the years.

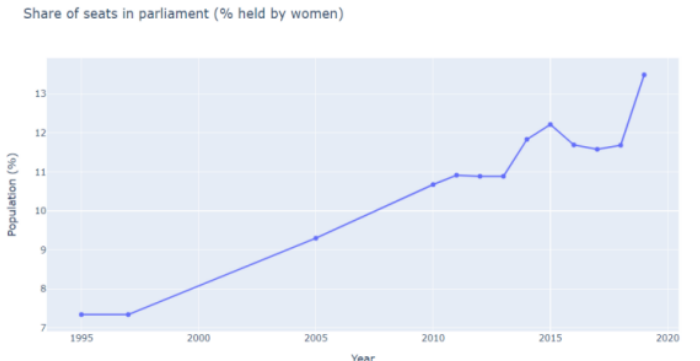

Fig. 11. Share of seats in parliament (\% held by women)
The share of seats held by women in parliament has almost doubled from $7.3 \%$ in 1995 to $13.5 \%$ in 2019 .

So to conclude, we can see that Social indicators play a very important part in a person's well-being as it influences many other factors such as Health, Education and Economy. Many social indicators have seen great improvement in the last few decades as now most people in rural areas have access to electricity, more people both in urban and rural receive social benefits and the number of women holding a seat in parliament has doubled since 1995. Along with this drop-out rate in primary education has also seen a slump. The disparity between men and women has also seen a decrease.

However, the disparity between the rich and poor in some indicators still seems to be increasing to this day. The gap between the income share held between the rich and poor is greater than ever and doesn't seem to be decreasing. Effort has to be taken to improve this sector to increase the well-being of poor people and lift them from the poverty line.

\section{B. Economic Factor:}

\section{B.1. GDP (Gross Domestic Product):}

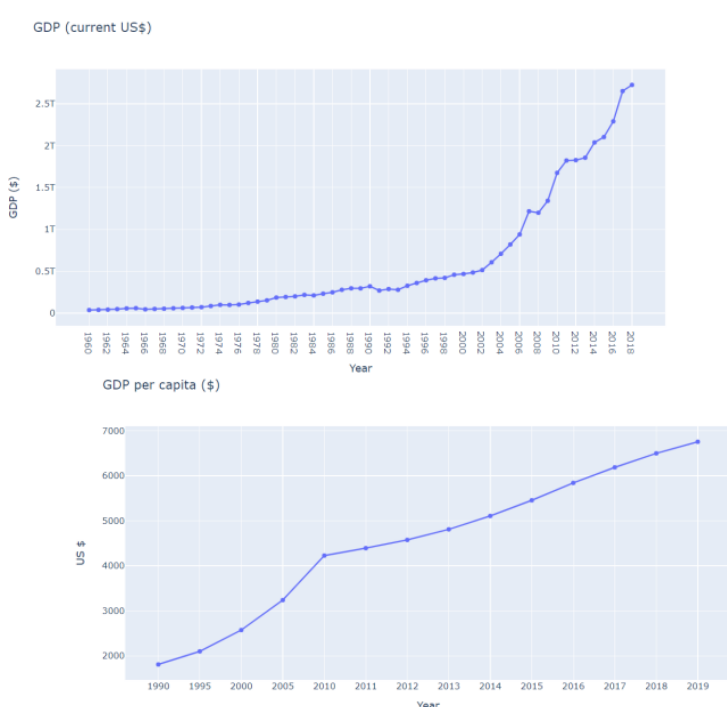

Fig. 12. Rate of change of GDP and GDP per capita

Since 1960 India's GDP has been increasing at an impressive rate. The GDP has gone from just \$37 Billion in 19060 to $\$ 2.7$ Trillion in 2018. Every decade has seen a massive increase, going from a 1.26 times increase from 1990 to 2000 to a 3.5 times increase from 2000 to 2010 . This decade is seeing a slight decrease with a GDP growth of 1.6 times from 2010. Along with this even the GDP per capita is increasing at a constant rate. It has shown a 5 times increase from $\$ 1809$ in 1990 to $\$ 6754$ in 2019.

B.2. Education expenditure: 


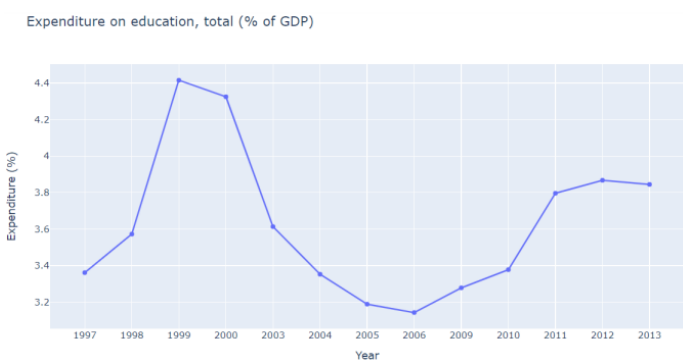

Fig. 13. Expenditure on education (\% of GDP)

The expenditure on education ( $\%$ of GDP) has been fluctuating from 1997. But it has remained constant in recent years at around 3.8\%. The expenditure peaked in 1999 at $4.4 \%$ following which it has shown a gradual decline hitting a minimum of $3.1 \%$ in 2006. But ever since 2006 the education expenditure has seen a constant rise.

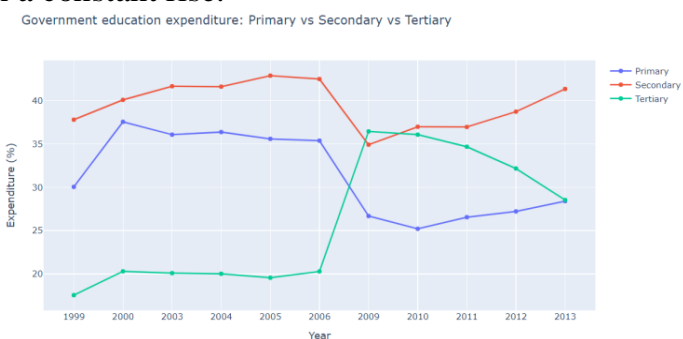

Fig. 14. Government education expenditure: Primary vs Secondary vs Tertiary

The average government expenditure on education has been highest for secondary education at $39.6 \%$, second highest for primary at $31.4 \%$ and lowest for tertiary at $26 \%$. Although tertiary education has the lowest average spending, it has exhibited the highest increase from 1999 to 2013 of $11 \%$. Primary education expenditure has only slightly increased from 1999 by a factor of $4 \%$. However, only secondary education expenditure has seen a dip, of $2 \%$, since 1999.

\section{B.3. Health Expenditure:}

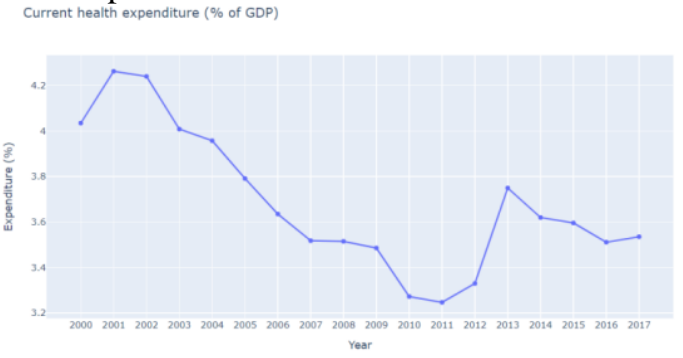

Fig. 15. Current health expenditure (\% of GDP)

Health expenditure (\% of GDP) has slumped from $4 \%$ in 2000 to $3.5 \%$ in 2017. Furthermore, the average health expenditure has decreased from $3.8 \%$ in the last decade compared to $3.4 \%$ this decade.

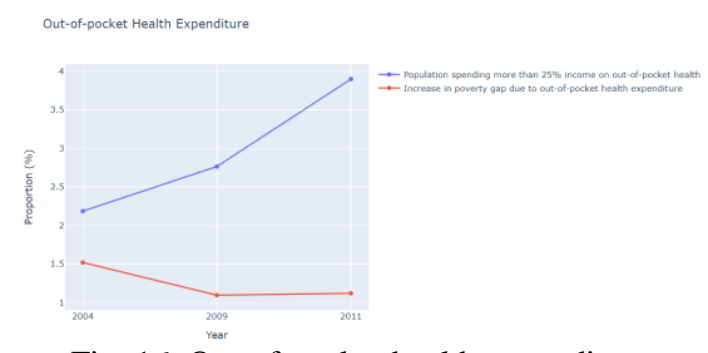

Fig. 16. Out-of-pocket health expenditure

The population spending more than $25 \%$ income on out-ofpocket health increased from $2.2 \%$ in 2004 to $2.7 \%$ in 2009 finally peaking at $3.9 \%$. The rate of increase in population is increasing as in 2009 it increased by $21 \%$ whereas in 2011 it increased by $29 \%$, which is an $8 \%$ increase in just 2 years. Also the increase in gap has also decreased from $1.5 \%$ in 2004 to $1.1 \%$ in 2009 following which it has more or less remained constant.

So to conclude, the above analysis illustrates that many economic indicators have shown a positive change. India's GDP and GDP per capita is the highest it has ever been and along with this expenditure on tertiary education has also risen. But apart from this various indicators have shown a slump. There has been a decrease in the government expenditure on both health and education in recent years. Furthermore, the population has witnessed an increase in out-of-pocket health expenditure which creates a burden on the poor.

\section{Health Factor:}

C.1. Tuberculosis Deaths:

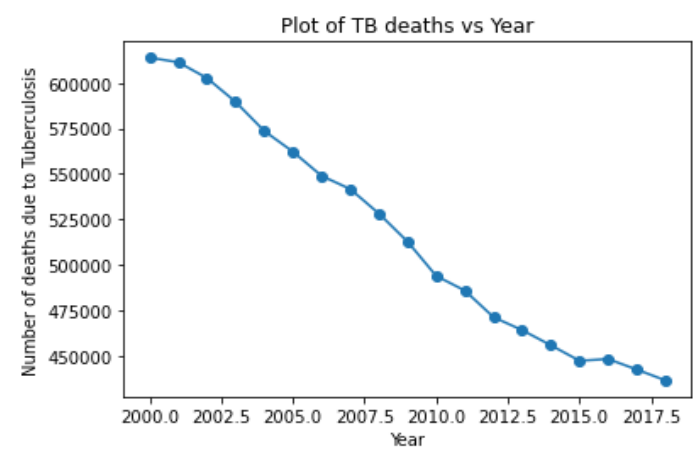

Fig. 17. Rate of TB deaths through the years

There has been a remarkable drop in the number of tuberculosis deaths over a period of 18 years. From 2000 to 2018, the number of tuberculosis deaths has fallen over $28 \%$ from over 6.1 lakh deaths in 2000 to just above 4.3 lakh deaths in 2018.

C.2 Life Expectancy \& Healthy Life Expectancy: 


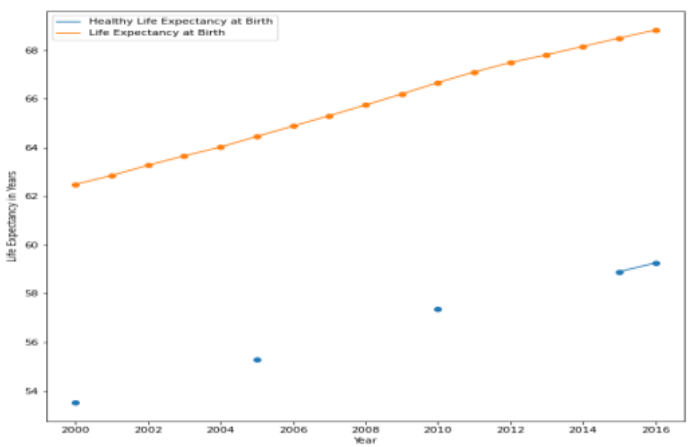

Fig. 18 Life expectancy vs Healthy life expectancy

Both regular life expectancy and healthy life expectancy have grown at almost the same steady rate of about $0.4-0.5$ years annually from the year 2000 to 2016 . Life expectancy has risen from 62.48 years in 2000 to 68.82 years in 2016; a growth of almost $10 \%$. Similarly, the healthy life expectancy has grown roughly $10.71 \%$ from 53.51 years to 59.25 years. While both have grown, the healthy life expectancy still has a long way to go before it reaches the value of regular life expectancy.

\section{C.3 Mortality Rates:}

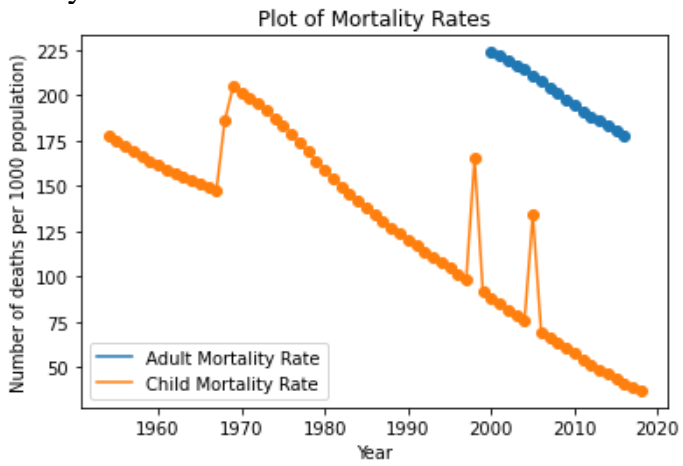

Fig. 19. Mortality Rates

The overall child mortality rate has shown much decline from the year 1954 to 2018. The government of India has clearly taken huge steps in reducing this saddening metric. While there was an undercounting of deaths of children from 1954 to 1967, the count has improved in quality and consistency since then. This is evident in the numbers - from 147 deaths per 1000 in 1967 to an average of about 188 deaths per 1000 in the years 1968 to 1975. Overall, the child mortality rate in India has fallen from a peak of 204 deaths per 1000 in 1969 to as low as 37 in 2018. This represents a spectacular drop of almost $82 \%$. The rate of decline of the adult mortality mirrors the child mortality rate at about $3 \%$ per annum.

To conclude, the health metrics and the health of an Indian citizen has become significantly better when compared to the early post-independence era, but there is still a lot of potential for improvement.

\section{Education Factor:}




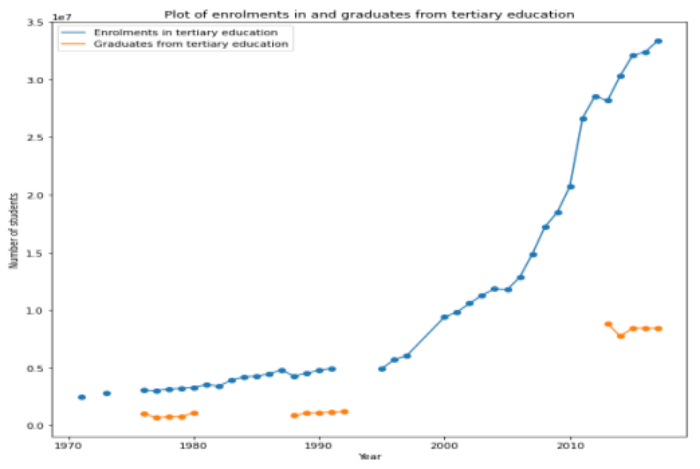

Fig. 22. Enrollments and graduates from tertiary education

The number of enrollments in institutions providing tertiary education has risen from 24.7 lakh in 1971 to over 3.3 crore in 2017. While the rate of increase was modest till 1997, it has risen by roughly $19 \%$ every year since then. This is a very positive indication of growth and development of the nation's youth and the capability of families to educate their children.

Despite the staggering growth in the number of enrollments for tertiary education, the number of tertiary graduates does not follow the trend of huge increases per annum. The number of tertiary graduates remains constant at an average of 9.7 lakh per year. This metric increases to 83.7 lakh per year. Still, the rate of growth per annum during this period between 2013 and 2017 remains negligible at $0.003 \%$ per annum.

This discrepancy between tertiary education enrolment and graduates points to the lack of quality education being dispersed at the educational institutions and to financial ability of families to see their children's education through to the end.

\section{E. Does increase in GDP per capita affect life expectancy?}

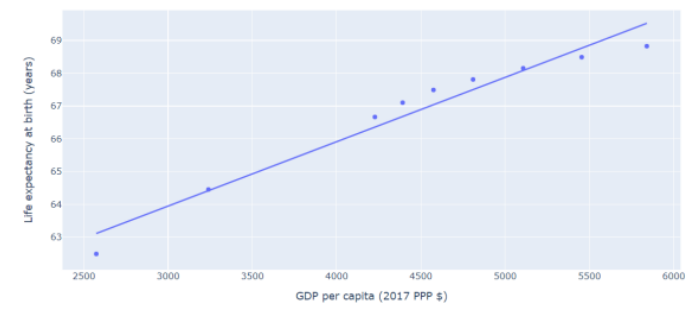

Fig. 23. GDP per capita (\$) vs Life expectancy (years)

GDP per capita shows a strong positive correlation with life expectancy of a person at birth having a correlation coefficient of 0.97. Regression analysis on these indicators reveal that an increase of $\$ 1$ in the GDP per capita raises the life expectancy by 0.002 .

\section{F. Impact of GDP per capita on rate of female students enrollment}

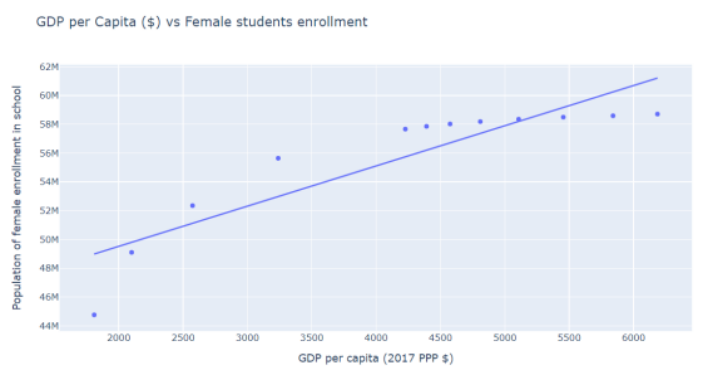

Fig. 24. GDP per capita (\$) vs Female students enrollment

The correlation coefficient of GDP per capita and student female enrollment is 0.894 which emphasizes that there is a strong positive correlation. On performing regression analysis we learn that an increase of \$1 in GDP per capita results in an enrollment of 2792 students.

\section{G. Impact of Literacy rate on the Average age of first marriage of women}

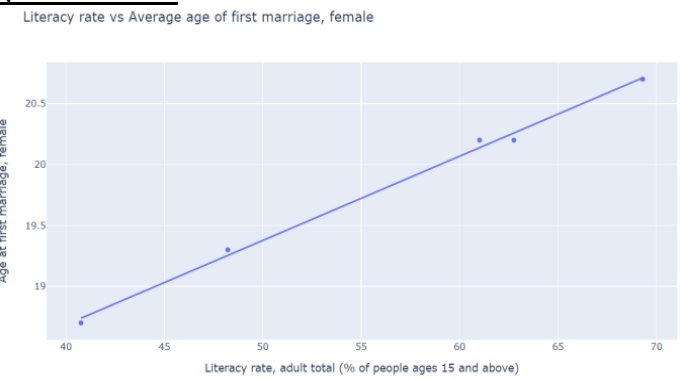

Fig. 25. Literacy rates vs Average age of first marriage, female

A correlation coefficient of 0.99 points to the fact that literacy rate has a strong positive impact on the average first marriage age of women. Regression analysis on these indicators highlights that an increase of $1 \%$ in the literacy rate increases the average age by 0.07 . Moreover, the intercept value indicates that if the literacy rate is 0 then the average first marriage age of women would be 15 , which is much lower than the legal age of marriage.

\section{H. Influence of increase in share of seat of women in parliament on female enrollment rate}

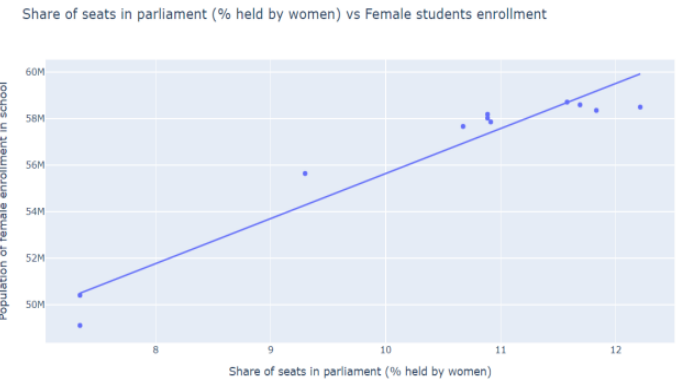

Fig. 26. Share of seats in parliament held of women (\%) vs Female students enrollment 
A correlation coefficient of 0.96 indicates that there is a strong influence of share of seats held by women in parliament on enrollment of women in school. Upon analyzing the regression coefficient we find out that an increase of $1 \%$ in the share of seats held by women in parliament leads to an increase of 1,936,018 female enrollment in school. Additionally, the value of the intercept shows that if there were no woman holding a seat in parliament, then the number of female enrollment would only be $36,278,902$, which is $39 \%$ less than the enrollment rate right now.

\section{RESULTS AND DISCUSSION}

We have calculated the index scores and the final wellbeing score decade-wise instead of yearly as the above analysis suggests that major change in trends occur every decade. OWBS relies on each of the four indexes having a valid score. That is why in Table 1 we have not calculated the OWBS for a decade if one or more of the indexes is missing.

Table-1 Comparison of individual index scores and final wellbeing score (OWBS)

\begin{tabular}{|l|c|c|c|c|c|}
\hline Decade & Social & Health & Economy & Education & OWBS \\
\hline $\begin{array}{l}2010- \\
2018\end{array}$ & 0.6726 & 0.6643 & 0.4964 & 0.2481 & 0.5840 \\
\hline $\begin{array}{l}2000- \\
2009\end{array}$ & 0.5521 & 0.6127 & 0.3966 & 0.1823 & 0.4914 \\
\hline $\begin{array}{l}1990- \\
1999\end{array}$ & 0.5220 & 0.4661 & 0.1401 & 0.1176 & 0.3721 \\
\hline $\begin{array}{l}1980- \\
1989\end{array}$ & - & 0.2974 & - & 0.0838 & NA \\
\hline $\begin{array}{l}1970- \\
1979\end{array}$ & - & 0.1162 & - & 0.0608 & NA \\
\hline $\begin{array}{l}1960- \\
1969\end{array}$ & - & 0.1876 & - & - & NA \\
\hline $\begin{array}{l}1950- \\
1959\end{array}$ & - & 0.1464 & - & - & NA \\
\hline
\end{tabular}

As shown in Table 1, all four sectors have shown impressive growth each decade. The index scores of this decade are the highest in all four. Social and health indexes have exhibited the highest rate of increase in the last two decades which is corroborated by [17-19]. This can be attributed to the numerous health [20] and social [21] policies that have been put in place in recent years. The education index is on the lower side. However, it has risen by $36 \%$ from the last decade which is a considerable rate of increase. The sources of $[22,23]$ validate the above findings.

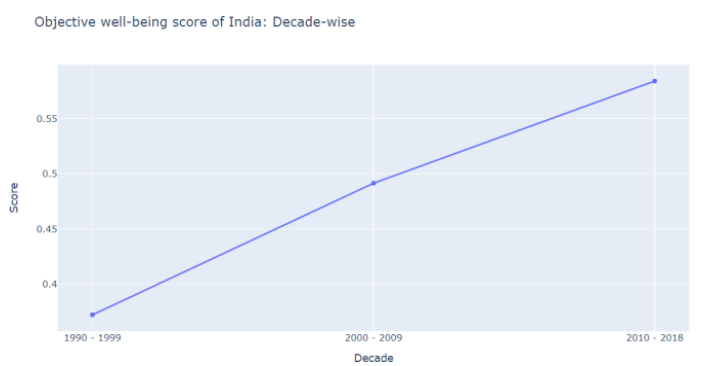

Fig. 27. Object well-being score of India: Decade-wise

India got a final OWBS of 0.5840 , which suggests that the well-being of the population is good however there is a lot of room for improvement. The OWBS has shown a $32 \%$ increase from 0.3721 in 1990 s to 0.4914 in 2000 s and a $20 \%$ increase till the present decade. An improvement in the economic and health sectors can significantly bump up the OWBS in the following years.

\section{CONCLUSION}

India has made great strides in the overall development of its health, economic, educational, and social sectors. This pace picked up after 2000 and reached maximal heights in the 2010s. The de-nationalization policies and the subsequent opening up of the markets in the 1980s and 1990s [24] seems to have been the primary mover of this growth that we see today. The quality of life and wellbeing of the average citizen of India has risen leaps and bounds from its independence-era to the current day.

Despite this, Indian bureaucrats and policy makers must realize the vast potential for improvement, particularly in the sectors of literacy, good quality education, women empowerment, economic inequality, contagious disease management, and environmental pollution, for significantly improving the lives of the citizens, especially the underprivileged and socially oppressed population.

\section{REFERENCES}

[1] "well-being". Cambridge Dictionary. 1995.

[2] The World Bank, Sustainable Energy for All (SE4ALL).

[3] The World Bank, World Development Indicators Databank.

[4] UNESCO, The UNESCO Institute for Statistics (UIS).

[5] United Nations Development Programme. Human Development Index (HDI).

[6] Abraham H. Maslow. "Motivation and Personality". 1954.

[7] Centers for Disease Control and Prevention (CDC), "WellBeing Concepts".

[8] Office of National Statistics (ONS), "Measuring National Well-being: Quality of Life in the UK". 2018. 


\section{International Journal of Engineering Applied Sciences and Technology, 2021 \\ Vol. 6, Issue 2, ISSN No. 2455-2143, Pages 151-160 \\ Published Online June 2021 in IJEAST (http://www.ijeast.com)}

[9] Crisp, Roger. "Well-Being". The Stanford Encyclopedia of Philosophy. Metaphysics Research Lab, Stanford University. 2017.

[10] World Health Organisation, "The World Health Observatory"

[11] Kirch W. Pearson's "Correlation Coefficient". In: (eds) Encyclopedia of Public Health. 2008 Springer, Dordrecht. https://doi.org/10.1007/978-1-4020-5614-7_2569.

[12] United Nations Development Programme. "Human Development Reports - Technical Notes". 2020.

[13] Angus Campbell. "The Sense of Wellbeing in America". 1981.

[14] David Hanscom. "Mental Health Is More Critical Than Physical Health". January 15, 2020.

[15] Michael Marmot. "The Influence Of Income On Health: Views Of An Epidemiologist". 2002.

https://doi.org/10.1377/hlthaff.21.2.31

[16] Victoria Howard. "Alan Turing - The Tragic Life Of The Genius Who Cracked Enigma”. 2020.
[17] "Inter Caste Marriage in India: Evidence from National Family Health Survey"

[18] Magadh University. "Religious and Social Reform of India - The Indian Renaissance"

[19] Pew Research Center. "Religion in India: Tolerance and Segregation". 2021.

[20] Betz, Joachim. "India's social policies: Recent changes for the better and their causes". 2019.

[21] Shankardass, K., Muntaner, C., Kokkinen, L. et al. "The implementation of Health in All Policies initiatives: a systems framework for government action". Health Res Policy Sys. 2018. https://doi.org/10.1186/s12961-018-0295-Z

[22] Sushma Berlia. "Educational Reforms in India". 2008.

[23] Klemensits Péter. "Education Reform in India - The Power of Knowledge and Information". 2017.

[24] "Narasimha Rao - a Reforming PM". news.bbc.co.uk. BBC News. 23 December 2004. 